\title{
Challenges and Opportunities of Handicraft Production Among Afar Women: The Case of Aysaita District
}

\author{
MOHAMMED NURU KEMAL
}

\begin{abstract}
Diversification is a matter of survival for most poor pastoralists, where as for the relatively wealthy pastoralists it is a strategy of accumulation or investment (Fiona, 2007). Both men \& women pastoralists participate in income generating activities. However, their participation in income generation activities compounded with many constraints. This article explores the major challenges and opportunities of hand craft production among Afar women pastoralists. In a general term, the study employed descriptive research design. Consequently, survey questionnaire was administered for a total of 24 women pastoralist and agro pastoralist of Berga kebele.Handicraft production is an important source of income pastoralists (especially women). However, the potential of this commercial avenue has not been fully realized. Some reasons for this include; limited market, lack of storage and production areas, shortage of finance for the purchase of quality raw materials and production equipment; and lack of skills for improved production.Traditionally, handicrafts were only produced for household use and for gifts. The community has realized that tourists and other visitors are interested in buying these items and that they can generate an income. Household items, leatherwork, carpets and ropes and traditional weaponry are popular with visitors to the region. Most of the traditional handicrafts are produced using locally available palm tree leaves. The Afar mostly use brass or bronze to create jewelry. The Regional culture and tourism bureau should arrange cultural exhibitions and promote these cultural produces at federal and international levels that increase economic incomes of households and popularize their products.All stakeholders including women and Youth bureau, cooperative offices and pastoral agriculture development bureau should work in collaboration in order to create market linkage with other traders.Research Institutions and Development agents should work closely to solve raw materials shortages and make accessible for them in their locality. In general, there should urgently need to organize the producers, establish microfinance/ rural saving and lending systems and provide training on improved production techniques and to create market channels. This will secure a more stable livelihood for the Afar people.
\end{abstract}

Keywords: Afar, Pastoralism, Pastoralist Handcraft, Production, Women pastoralist

DOI: $10.7176 / \mathrm{JCSD} / 59-01$

Publication date:May $31^{\text {st }} 2020$

\section{BACKGROUND AND JUSTIFICATION}

Today there are many pressures on pastoralists to diversify their livelihood beyond a reliance on livestock. The challenges of pastoralists originate from both anthropogenic and natural causes. Climatic fluctuations, animal disease, market failure \& conflict are major problems of pastoralists among others (Little, 2001). Within pastoralist societies, the use of labor is highly gender specific and women have traditionally played important roles in the management of natural resources (WISP, 2007).

Diversification is a matter of survival for most poor pastoralists, where as for the relatively wealthy pastoralists it is a strategy of accumulation or investment (Fiona, 2007). Both men \& women pastoralists participate in income generating activities. However, their participation in income generation activities compounded with many constraints. The major challenges include lack of necessary skills \& knowledge to make the right choices and identify the most successful income generation activity; lack of access to capital for starting up a business; lack of access to appropriate technology; and lack of access to markets.

Making and selling crafts (such as baskets, bags, mats \& leather goods) represents one of the diverse livelihood strategies of pastoralists in Ethiopia. Handicrafts are made using local knowledge, skills \& creativity, which draw on the surrounding environment for their materials \& inspiration. Many Non-Timber Forest Products including grasses, reeds, gourds, palm leaves \& tree bark are worked to make mats, baskets \&bowls. They mainly produce crafts for use with in the household and consider as part of cultural identity \& traditions. Making handicrafts reflects gender differences between men \&women as well as their different roles \& responsibilities within the household \& community.

In Afar men make furniture, bracelets, and knives, milking bowls, sandals and spoons. Women make baskets, brooms, goatskin storage bags, fans, milking vessels, necklaces and sleeping mats.

Participation in income generation activities, particularly of women may be limited by a range of factors including level of mobility \& resources, cultural \& religious constraints and the type of task in the chain of activities. This study aimed at to look in to the challenges and opportunities of handicraft productions among Afar women in Aysaita woreda. 


\section{OBJECTIVES}

The overall objective of the study was to look into the challenges and opportunities of traditional handcraft production among Afar women in Aysaita woreda.

\section{Specific Objectives of the Study}

The specific objectives of the study include:

- Assess the demographic characteristics of women who engaged in the traditional handcrafts production in the study area;

- Identify types and purposes of traditional handcrafts products that produced by women in the study area;

- Pin point the major constraints \& opportunities of women handicraft producers in their production;

- Suggest possible solutions that improve income generation potential of women's traditional handcrafts production activity in the future.

\section{Methodology/ Methods and Materials}

\subsection{Descriptions of the Study Area}

The study was conducted in Aysaita woreda of zone one/ Awusi Resu administrative. The woreda has a total of 13 kebeles of which 11 are rural kebeles and two are urban kebeles. It has total area of about 155374 hectares. The woreda shares border with Afambo woreda in the south east, Djibouti in the east, Elidaar woreda in the north and, and Dubti woreda in the west and south west. The total population of the woreda is $47,210(25,152$ male and 22,058 female). From the total population of the woreda, rural residents consist of about 31,162 (66 per cent) and the remaining 16,048 (34 per cent) are urban residents. From the total rural residents of the woreda, 16,971 are male and 14,191 are female that accounts 54.5 per cent and 55.5 per cent respectively (CSA, 2007). Aysaita town is the capital of the woreda and located near river Awash at its lower course. The town has founded by Awsa sultanate and until 2003/4, it has been served as a capital of the sultanate as well as different forms of modern government of the region.

\subsection{Methods and Materials}

In a general term, the study employed descriptive research design. And it was undertaken in Berga kebele in which was selected purposefully. Because, it is the main potential and source of women's traditional handcraft products in the woreda. From the kebele 24 households were selected at random basis. Consequently, survey questionnaire was administered for a total of 24 women pastoralist and agro pastoralist of Berga kebele.

Both qualitative and quantitative data were collected using questionnaire. In addition to this, secondary data was collected from secondary data sources using document review. In order to analyze data, descriptive statistics, such as percentages and averages were used. And for this purpose, Statistical Packages for Social Sciences (SPSS) soft ware program of a computer, version 20 was used.

\section{DISCUSSIONS AND FINDINGS}

\subsection{Demographic Characteristics of the Respondents}

All the 24 sample respondents were gave their responses. Regarding the age of respondents, the majority of them were found within 35 to 44 years age category. These constitute about 37.5 per cent of the total respondents. Among the total number of respondents seven of them were found within 15 to 24 years of age group which constitute about 29 per cent. On the other hand 21 per cent of respondents were also found within 25 to 34 years age category. While the remaining 12.5 per cent of respondents were found within 45 to 54 years age group.

In terms of religion all the respondents were Muslims. And regarding to their educational status, 16 respondents were illiterate and eight were literate (i.e. read and write) that constituted about 67 per cent and 33 per cent of the total respondents respectively. In terms of the respondents' marital status, most of the respondents (96 per cent) were responded as they were currently married and the remaining four per cent were widowed. Accordingly, 95 per cent of the respondents were male headed households and the remaining five per cent of them were female headed households.

Regarding to their family size, about 42 per cent of the respondents had a family size of seven members; and those respondents who had a family size of six members constitute about 21 per cent of the total respondents. Besides, respondents who had a family size of four, five and eight members constituted about 12,17 , and eight per cents of the total respondents respectively. The average family size of the respondents was about 6.15 ; it is higher than the national and regional household size average that is 4.3 . Table one below shows demographic characteristics of the respondents. 
Table1. Demographic Characteristics of the Respondents

\begin{tabular}{|c|c|c|c|c|}
\hline Characteristics & Category & Number & Per cent & Remark \\
\hline \multirow[t]{8}{*}{ Age } & $<15$ years & - & - & \\
\hline & $15-24 »$ & 7 & 29.17 & \\
\hline & $25-34 »$ & 5 & 20.83 & \\
\hline & $35-44 »$ & 9 & 37.5 & \\
\hline & $45-54 »$ & 3 & 12.5 & \\
\hline & $55-64 »$ & - & - & \\
\hline & $+65 \gg$ & - & - & \\
\hline & Total & 24 & 100 & \\
\hline Religion & Muslims & 24 & 100 & \\
\hline \multirow[t]{3}{*}{ Education } & Illiterate & 16 & 66.67 & \\
\hline & Literate & 8 & 33.33 & Can read and write \\
\hline & Total & 24 & 100 & \\
\hline \multirow[t]{3}{*}{ Marital status } & Currently married & 23 & 95.83 & \\
\hline & Widowed & 1 & 4.17 & \\
\hline & Total & 24 & 100 & \\
\hline \multirow[t]{6}{*}{ Family size } & 4 members & 3 & 12.5 & \\
\hline & 5 members & 4 & 16.67 & \\
\hline & 6 members & 5 & 20.83 & \\
\hline & 7 members & 10 & 41.67 & \\
\hline & 8 members & 2 & 8.33 & \\
\hline & Total & 24 & 100 & \\
\hline
\end{tabular}

Source: Survey result of the study

\subsection{Respondents' Main sources of income}

According to the respondents, livestock rearing and crop production are their main income sources. Accordingly, they are considered as pure agro pastoralists. In addition, their family members were also engaged in various income generating activities. Some of their income sources in which the respondents and their families engaged in includes:

- Selling of livestock products (i.e. milk,);

- Selling of crops and animals feed;

- Selling of charcoal; and

- Selling of handcraft products.

Particularly traditional handcrafts production have made by all the respondent women in the study area.

\subsection{Traditional Handcraft Production Practices among the Afar Women}

\subsubsection{Types of materials produced and purposes}

Some of the handicrafts produced by the Afar community include; churning butter bags, baskets, jewelry, butter storage bags, combs, grain storage bags, water containers, mat/carpet and other utensils.

According to the respondents all the sample women were handcraft producers. Most of them were engaged in the activity for more than five years. Their main products include- Kaunta, Sesena, Fidima Gedibo, Sefilla, Mesgeja and Ayena. Others include dieting mats, hand fans, brooms, ropes, mats for floor/roof covering and prayer mats.

Table2. Traditional handcraft Products of Afar Women

\begin{tabular}{|l|l|l|}
\hline Products in Afar language & Purposes of the product & Remark \\
\hline Kaunta & milking vessels & \\
\hline Sesena & carpet & \\
\hline Fidima & mat/carpet & \\
\hline Gedibo & food plates & \\
\hline Sefilla & Food plate & \\
\hline Mesgeja & Praying mate & \\
\hline Ayena/Koora/ & Milking plate & \\
\hline Olloyta & sleeping mats & \\
\hline
\end{tabular}

\section{Source: Survey result of the study}


Fig1, some produce of Afar women and production methods

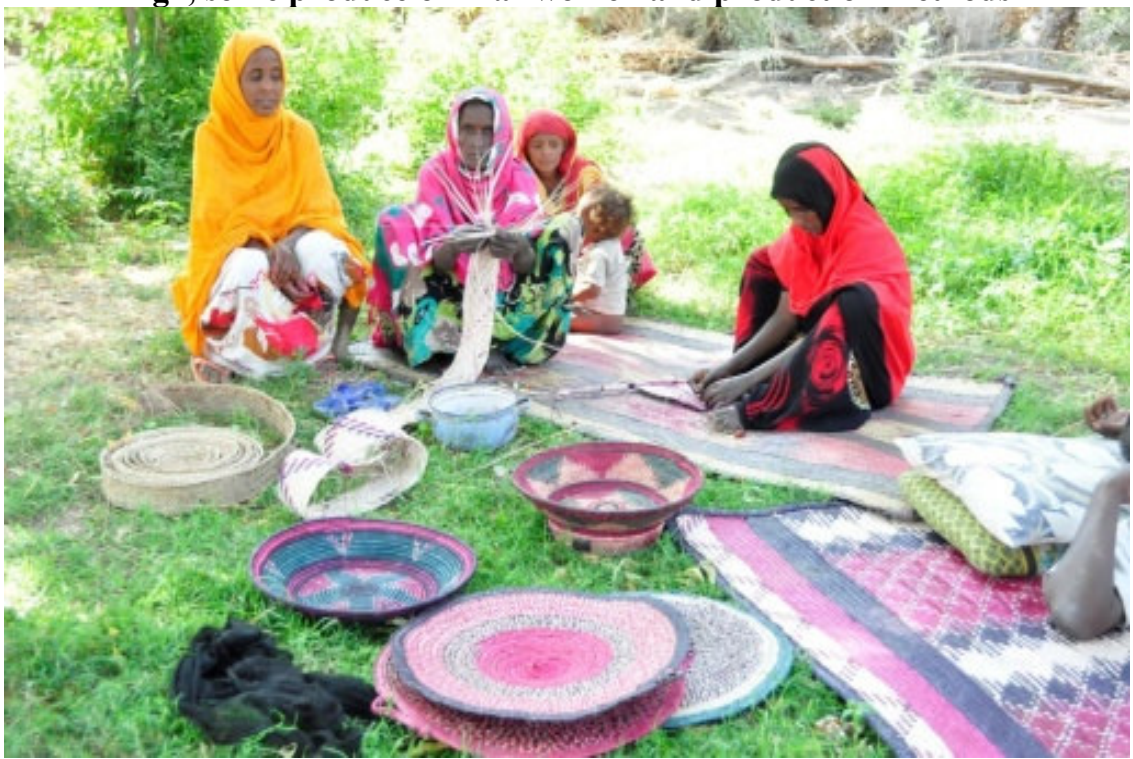

\subsubsection{Input and techniques of Production}

The production process of handicrafts uses locally available raw materials like palm leaves and is labour intensive because it is manual, which often affects quality. They have used different vegetation types for their handcraft production as raw materials such as Beleele, Alaytoye,Gereytu and Temirtu. They have also used various parts of these trees such as stems, branches, leaves and barks as raw materials. The dried palm tree leaves are placed in a big pot and boiled for $1-2$ hours. To ensure the smoothness of every piece, the leaves are turned frequently using a long fork. After boiling the leaves, they are put in a big basin to cool. Some of the leaves are mixed with three or more type of dye and cooking oil. The purpose of cooking oil is to fasten the dye to the leaves. The women then use the processed or raw leaves to produce various products using sewing.

Fig2. Handcraft Marketing in Aysaita woreda

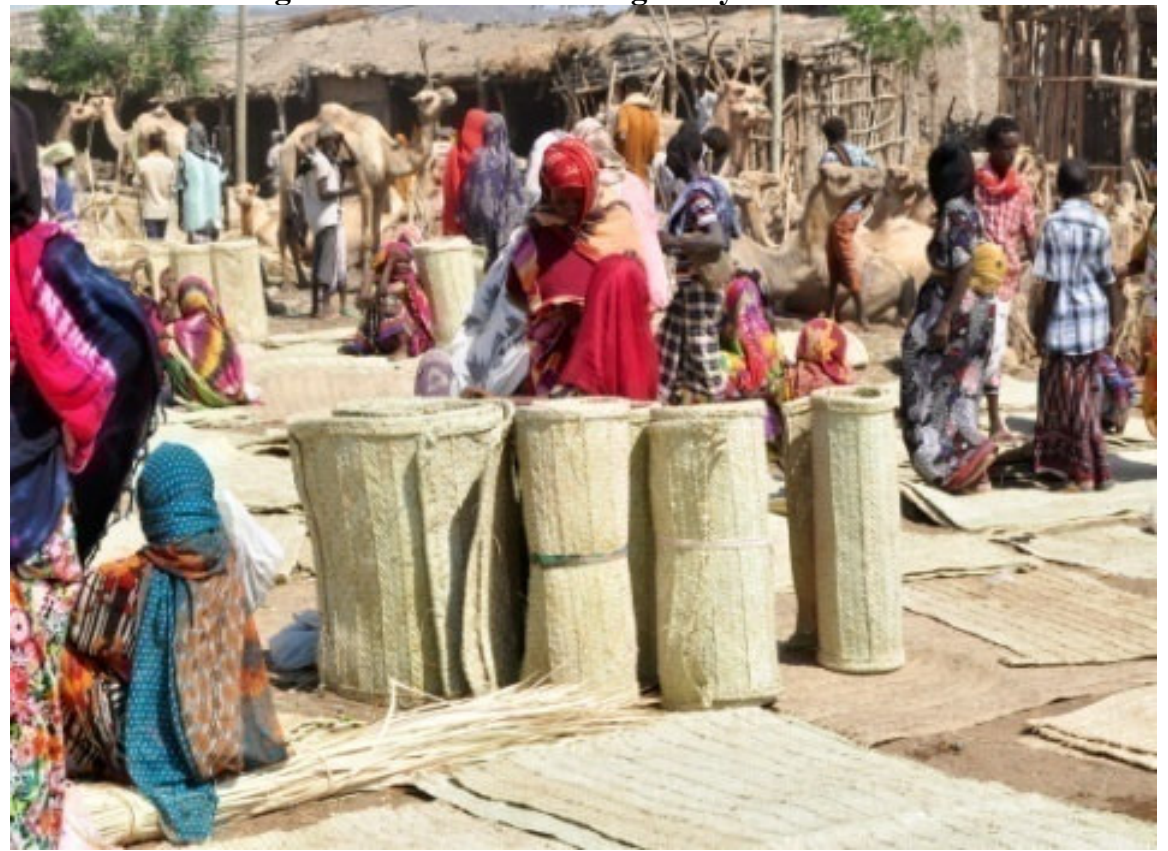

\subsubsection{Economic contribution of handeraft production and Ownership of income gained from selling of} products

According to the respondents, the producer is the owner of handcraft products income. They used their income for clothing, utensils, jewelry and to buy food for households' consumption.

4.3.4. Production Problems encountered the handcraft producers

Several studies reviled that traditional handcraft producers have constrained by many problems. Lack of necessary skills \& knowledge to make the right choices and to identify the most successful income generation activity; lack 
of access to capital for starting up a business; lack of access to appropriate technology; and lack of access to markets are some the major constraints of traditional hand craft producers.

Shortage of raw materials, workloads on women and time consumption are the major problems of handcraft producers of the kebele. They obtained the raw materials from market in which is less than five kilometer far from their homesteads. The respondents explained that as they have faced with raw materials shortage problem. The majority $(70 \%)$ of them replied that the shortage is occurring during winter season; where as 30 per cent of the respondents responded as they faced with the problem during summer season.

The availability of raw materials for their handcraft production varies from season to season with in a year. As table three below shows most of the respondents faced with high shortage of raw materials during winter/Hagay/ season of a year. The local people need assistance to be able to improve on the quality of their products.

Table3. Producers' Shortage of raw materials in different seasons

\begin{tabular}{|l|l|l|l|}
\hline Seasons & No of respondents & Percent & Remark \\
\hline Winter/Hagay & 17 & 70.83 & \\
\hline Summer/Karma & 5 & 20.83 & \\
\hline Spring/ & 2 & 8.33 & \\
\hline Total & $\mathbf{2 4}$ & $\mathbf{1 0 0}$ & \\
\hline
\end{tabular}

Source: Survey result of the study

\section{Conclusion and recommendation}

\subsection{Conclusions}

Most Afar communities have received food aid for the past 10 years. Their livestock base is seriously depleted and cannot support the ever-growing human population. Diversification is not an option anymore; the Afar must identify alternative livelihoods for their survival. Hand craft production and marketing activities, particularly by pastoral women, is one of the viable source of income for pastoralists in the region.

Handicraft production is an important source of income pastoralists (especially women). However, the potential of this commercial avenue has not been fully realized. Some reasons for this include; limited market, lack of storage and production areas, shortage of finance for the purchase of quality raw materials and production equipment; and lack of skills for improved production.

Traditionally, handicrafts were only produced for household use and for gifts. The community has realized that tourists and other visitors are interested in buying these items and that they can generate an income. Household items, leatherwork, carpets and ropes and traditional weaponry are popular with visitors to the region. Most of the traditional handicrafts are produced using locally available palm tree leaves. The Afar mostly use brass or bronze to create jewelry.

\subsection{Recommendations}

The Regional culture and tourism bureau should arrange cultural exhibitions and promote these cultural produces at federal and international levels that increase economic incomes of households and popularize their products.

All stakeholders including women and Youth bureau, cooperative offices and pastoral agriculture development bureau should work in collaboration in order to create market linkage with other traders.

Research Institutions and Development agents should work closely to solve raw materials shortages and make accessible for them in their locality.

In general, there should urgent need to organize the producers, establish microfinance/ rural saving and lending systems and provide training on improved production techniques and to create market channels. This will secure a more stable livelihood for the Afar people.

\section{References}

Andrew.R, Getachew .M and Fiona;eds (September 2007) Gender \& Pastoralism Vol 1: Rangeland \& Resource Management in Ethiopia. SOS Sahel Ethiopia P.O. Box 3262 Addis Ababa Ethiopia

APD (2002) Women's Rights in Islam and Somali Culture. Hargeysa: UNICEF.

APD \& Interpeace. (2006) From Plunder to Prosperity: Resolving Resource-Based Conflict in Somaliland. Hargeysa: APD \& Interpeace. www.apd-somaliland.org

Athoo, R. (2002) "Pastoral Women in Resource Decision-Making: The Case of the Maasai of Kajiado District, Kenya" RECONCILE Discussion Paper. Unpublished.

Ayalew Gebre (1997) "Conflict Over Land Use: Pastoralism, Commercial and State Agriculture, The Case of Afar", pp. 358-77. In F. Katsuyoshi et al (eds.) Ethiopia In Broader Perspective (vol. 2). Kyoto: Shokado.

Ayalew Gebre (2004) "When Pastoral Commons are Privatised: Resource Deprivation and Changes in Land Tenure Systems Among the Karrayu in the Upper Awash Valley Region of Ethiopia". Paper Submitted to the 10th Biennial Conference of the Association for the Study of Common Property (IASCP), Oaxaca, Mexico, 
August 9-13, 2004.

Bandyopadhyay, R. (2005) "Sustainable Development and 'Gender': The Experience of Participatory Forest Management in West Bengal, India". Unpublished Paper for Jadavpur University, India.

Bates, L. (2002) Smoke Health and Household Energy. Issues Paper No. R8021. Rugby: Intermediate Technology Development Group. www.practicalaction.org

BCFMP (1999) "Gaining a Common Understanding: The Core Concepts of Collaborative Forest Management" Internal Project Document.

CARE International in Ethiopia (1994) "CARE Borana Rangelands Development Project: Socio-Economic Baseline Study". Unpublished Project Document.

Coppock, D. L. (1993) "Pastoral Women Harvest Hay for Calves". www.metafro.be

Rangeland and Resource Management in Ethiopia

Coppock, D. L. (1994) The Borana Plateau of Southern Ethiopia: Synthesis of Pastoral Research, Development and Change 1980-91. ILCA Systems Study. Addis Ababa: ILCA.

Dasgupta, T., Roy, A. \& Chattopadhyay, R. (2006) "Gender Justice in the Frame of Joint Forest Management in Indian Context: A Case-Study from Nayagram Block of West Midnapore, West Bengal" Anthropologist 8(3): 161-166. www.krepublishers.com

Devereux, S. (2006) Vulnerable Livelihoods in Somali Region. Brighton: Institute of Development Studies.

Doss, C. R. \& McPeak, J. G. (2005) "Are Household Production Decisions Cooperative? Evidence on Pastoral Migration and Milk Sales from Northern Kenya" Yale University Economic Growth Center Discussion Paper No. 906. www.econ.yale.edu

WISP, 2007. Power, equity, gender and decision making in pastoralist natural resource management. WISP POLICY BRIEF NO. 7, June, 2007. 